\title{
Gabapentin for treatment of restless legs syndrome among hemodialysis patients; a pilot study
}

\author{
Seyed Majid Mousavi Movahed ${ }^{1}$, Gholamreza Alizadeh Attar ${ }^{2}$, Fatemeh Hayati ${ }^{2}$, Shahla Ahmadi Halili², \\ Leila Sabetnia ${ }^{2}$, Seyed Seifollah Beladi Mousavi ${ }^{2 *}$
}

${ }^{1}$ Department of Internal Medicine, Tehran University of Medical Sciences, Tehran, Iran

${ }^{2}$ Chronic Renal Failure Research Center, Ahvaz Jundishapur University of Medical Sciences, Ahvaz, Ira

\section{A R T I C L E I N F O}

Article Type:

Original

\section{Article History:}

Received: 27 February 2018

Accepted: 4 June 2018

ePublished: 19 June 2018

\section{Keywords:}

End-stage renal disease

Gabapentin

Restless legs syndrome

Hemodialysis

\begin{abstract}
A B S T R A C T
Introduction: Unfortunately the restless leg syndrome (RLS) is a neglected issue among hemodialysis (HD) centers.

Objectives: The aim of our study was to find the efficacy of gabapentin at a low dose of $100 \mathrm{mg}$ three times a week among HD patients with RLS.

Patients and Methods: Around 21 patients with fulfilled the criteria of RLS were randomized to receive either gabapentin $(100 \mathrm{mg})$ or placebo after HD session for 4 weeks. After 2 weeks of washout period, the patients were switched from gabapentin to placebo or placebo to gabapentin for another 4 weeks. Severity of RLS symptoms before and after management with medication or placebo was evaluated with standardized questionnaire.

Results: Twenty-one patients ( 10 females and 11 males with mean age of 58 years) were enrolled to the study. Before the study, all patients had questionnaire scores of 16 or greater and the mean score was $24.19 \pm 7.96$. After gabapentin administration (before or after crossover), the mean score significantly decreased from $24.19 \pm 7.96$ to $19.24 \pm 9.87(P=0.04)$. The mean score before and after placebo administration (before or after crossover) were $24.19 \pm 7.96$ and $18.89 \pm 11.15$ with no significant difference $(P=0.09)$.

Conclusion: According to the results of the study gabapentin at a dose of $100 \mathrm{mg}$ at the end of HD is a safe effective therapy for RLS. It can significantly reduce the intensity of RLS among these patients.
\end{abstract}

Implication for health policy/practice/research/medical education:

In a study on 21 hemodialysis patients ( 10 females and 11 males with mean age of 58 years), we found that gabapentin at a dose of $100 \mathrm{mg}$ is a safe effective therapy for restless legs syndrome. It can significantly reduce the intensity of restless legs syndrome among hemodialysis patients.

Please cite this paper as: Mousavi Movahed SM, Alizadeh Attar G, Hayati F, Ahmadi Halili S, Sabetnia L, Beladi Mousavi SS. Gabapentin for treatment of restless legs syndrome among hemodialysis patients; a pilot study. J Nephropharmacol. 2018;7(2):104-109.

\section{Introduction}

End-stage renal disease (ESRD) is one of the most common life-threatening diseases with poor outcomes $(1,2)$. It is defined as permanent and irreversible loss of renal function requiring renal replacement therapy including hemodialysis (HD), peritoneal dialysis, and or kidney transplantation $(1,2)$. Possibly owing to increasing prevalence of diabetes and hypertension, the proportion of these patients increases each year and imposes a major social and economic burden on countries (2-4).

Restless leg syndrome (RLS) is one of the most common neurological disorders among patients with ESRD both before and after the institution of dialysis (5). RLS is a sensorimotor movement disorder characterized by an unpleasant sensation in the legs and consequently urges patients to move the lower extremities. Patients often describe the sensation in various ways such as creeping, gnawing, crawling, itching, or even boring pain in the muscles or bones of the legs and occasionally in the arms. It usually occurs during inactivity or at rest and becomes worse at evening and night $(5,6)$.

A significant percentage of patients with ESRD have severe or very severe symptoms of RLS, ranging from $15 \%$ to $40 \%$. In some racial groups, the rate of RLS among ESRD patients is even reached to $83 \%$ (5-7). The pathogenesis of RLS among ESRD patients is not clear. 
However some factors including iron deficiency anemia, calcium/phosphate imbalance, central nervous system abnormalities and peripheral neuropathy secondary to uremia or the underlying cause of ESRD (such as diabetes) may predispose ESRD patients to develop RLS (6-9).

In most patients with RLS, this condition causes exhaustion, daytime fatigue, anxiety and depression, which significantly decreases quality of life. Activities of daily living are also strongly affected as a result of RLS among these patients (5-8). Moreover, it is suggested that RLS may be associated with increased risk of nocturnal hypertension as well as cardiovascular events and mortality among ESRD patients (7-9). However it seems that RLS is a neglected issue among dialysis centers and renal healthcare providers. There are few clinical trials regarding treatment of RLS among uremic patients. Various pharmacologic agents including levodopa, opiates, and benzodiazepines have been evaluated to prevent and or reduce intensity of RLS among uremic patients, however, the results are conflicting. According to few studies on this subject, no generally accepted treatment for RLS in uremic patients was provided (5-10).

\section{Objectives}

The aim of our study was to find the efficacy of gabapentin on the prevention and treatment of RLS among ESRD patients undergoing maintenance HD.

\section{Patients and Methods}

\section{Study design}

This study was a pilot investigation. A standardized questionnaire was applied for the evaluation of severity of RLS symptoms (8). Another questionnaire was also applied to collect general information of participant such as age, gender, vital signs, causes of renal failure, date and length of time receiving HD services and the record of administered drugs.

The criteria developed by International RLS Study Group (IRLSSG) were applied as diagnostic criteria for the diagnosis of RLS (8). Minimum criteria to support a diagnosis of RLS include, presence of four clinical characteristics; 1) a desire to move the limbs with or without dysesthesias; 2) motor restlessness, using different motor strategies such as walking or stretching to relieve unpleasant sensations; 3 ) symptoms onset or exacerbation with rest or inactivity, particularly when lying down or sitting, and 4) symptoms worse in the evening or at bedtime (circadian pattern) (8).

The drug (gabapentin) and placebo were offered to the participants free of cost. The period of study was 4 months from February 2014 to June 2014. The nature of the study was explained to the patients and written informed consents were obtained. The goal of the study was reduction of RLS symptoms. Primary end points of the study were treatment and or diminish the severity of RLS.

\section{Patients}

The study performed on HD patients at the Imam hospital, Ahvaz, Khuzestan province, southwestern, Iran. The ESRD was defined as permanent and irreversible advanced loss of kidney function due to any causes with creatinine clearance of less than $10-15 \mathrm{~mL} / \mathrm{min} / 1.73 \mathrm{~m}^{2}$ requiring maintenance $\mathrm{HD}$ therapy.

HD patients were evaluated for RLS according to the criteria of the IRLSSG. Patients with all of four were included to the study. At least two of diagnostic criteria for RLS resulting to a minimum score of 6 should constantly be existed.

Patients with the following characteristics were excluded; patients who had electrolyte disturbance, patients with abnormal neurological exam, and patients who had administered other medical treatment for RLS such as levodopa, benzodiazepine and opioids.

Patients with fulfilled the criteria of RLS were randomized to receive either gabapentin $(100 \mathrm{mg})$ or placebo, three times a week at the end of HD session for 4 weeks. After 2 weeks of washout period, the patients were switched from gabapentin to placebo or placebo to gabapentin for another 4 weeks.

Gabapentin (100 mg) or placebo was administered with $50 \mathrm{cc}$ water, 3 times weekly at the end of HD session under direct HD staff supervision. HD patients and HD staff were blinded to treatment assignment. Placebo, with the same color, size, and taste was manufactured by pharmacy department of Ahvaz Jundishapour University of Medical Sciences.

Subjects consenting to the protocol answered the questionnaire for the evaluation of severity of RLS symptoms before and after management with medication or placebo.

\section{Hemodialysis methods}

HD was conducted three times a week (each session was 4 hours) using Fresenius machines. Dialyzer membrane was polysulfone with bicarbonate- buffered dialysate (35-40 $\mathrm{mmol} / \mathrm{L})$. The other characteristics of dialysate was calcium of $1.5 \mathrm{mmol} / \mathrm{L}$, magnesium of $0.5 \mathrm{mmol} / \mathrm{L}$, sodium of $135-140 \mathrm{mmol} / \mathrm{L}$, potassium of $2 \mathrm{mmol} / \mathrm{L}$ and dialysate temperature of $36.58^{\circ} \mathrm{C}$. Blood flow rate was maintained at 250 to $400 \mathrm{~mL} / \mathrm{min}$ and the dialysate flow rate was maintained at $500 \mathrm{~mL} / \mathrm{min}$. The proportion of ultrafiltration during each $\mathrm{HD}$ session was determined individually by the nephrologist.

\section{Assessment of $\mathrm{Kt} / \mathrm{V}$}

$\mathrm{Kt} / \mathrm{V}$ was calculated at starting and end of HD session during gabapentin and placebo periods. For evaluation of $\mathrm{Kt} / \mathrm{V}$, blood sample for check of pre-dialysis blood urea nitrogen (BUN) was obtained immediately before HD session. For post-dialysis BUN, the blood flow rate was slowed to $100 \mathrm{~mL} / \mathrm{min}$ and after 15 seconds waiting, blood sampling was conducted. 


\section{Ethical issues}

The research followed the tenets of the Declaration of Helsinki; informed consent was obtained, and the research was approved by ethics committee of Ahvaz University of Medical Sciences. In this study, the full description of the processes and the importance of the study were explained to the patients who had volunteered and were selected. All of the assessments were non-invasive. This study was registered at the Iranian registry of clinical trial database (identifier: IRCT2014092319273N1; http://en.search.irct. ir/view/20107).

\section{Statistical analysis}

For statistical analysis, we used the SPSS 10.0 for Windows (SPSS, Inc., Chicago, IL, USA) and results are expressed as mean \pm SD. Scores from the questionnaire were tabulated and Wilcoxon signed-rank test was used to reveal the efficiency of gabapentin and placebo. Difference between parametric and nonparametric scores of two periods (gabapentin and placebo administration periods) were analyzed by student's paired $t$ test and McNemar's test. A $P$ value less than 0.05 were considered significant.

\section{Results}

Around $109 \mathrm{HD}$ patients with mean age of $52.6 \pm 15.3$ years were screened for RLS. Twenty-nine patients $(26.6 \%)$ fulfilled the criteria of RLS according to the criteria of the IRLSSG.

Before the beginning of the study, 8 patients were excluded; two patients because of kidney transplantation, three patients admitted in the hospital because of myocardial infarction in two and sepsis in one and three patients did not write informed consents.

Finally 21 patients (10 females and 11 males with mean age of 58 years) were enrolled to the study. Diabetic nephropathy was the cause of ESRD in 14 (66.7\%) of patients.

At the beginning of the study, the mean serum creatinine, hematocrit, calcium, phosphorus, parathyroid hormone, transferrin saturation and $\mathrm{Kt} / \mathrm{V}$ were $7.36 \pm 2.02$ $\mathrm{mg} / \mathrm{dL}, 33.7 \pm 5.4 \%, 8.6 \pm 0.5 \mathrm{mg} / \mathrm{dL}, 5.5 \pm 1.4 \mathrm{mg} / \mathrm{dL}, 682$ $\pm 290 \rho \mathrm{g} / \mathrm{mL}, 24.5 \pm 8.67 \%$ and $1.01 \pm 0.3$ respectively. Patients' data are listed in Table 1.

Before the study, all of 21 patients had questionnaire scores of 16 or greater. The mean score was $24.19 \pm 7.96$. Initially, 13 patients received gabapentin and 8 patients received placebo. During this period of the study one patient who received gabapentin, did not decide to complete the study because of vomiting and headache which occurred after gabapentin administration and therefore 12 patients received gabapentin in this period. After the washout, 12 patients received placebo and 8 patients received gabapentin. During this period of the study one patient who received placebo did not want to complete the study because of abdominal pain and diarrhea which occurred after placebo administration and therefore 11 patients received placebo in this period.

After gabapentin administration (before or after crossover), the mean score among participants who completed the study decreased from $24.19 \pm 7.96$ to $19.24 \pm 9.87(P=0.04$; Figure 1$)$.

The mean score before and after placebo administration

Table 1. Patients' data

\begin{tabular}{|c|c|c|c|c|c|c|c|c|c|}
\hline & Gender & Age (y) & Diabetes & Hematocrit (\%) & $\mathrm{Kt} / \mathrm{V}$ & $\begin{array}{l}\text { Calcium } \\
\text { (mg/dL) }\end{array}$ & $\begin{array}{c}\text { Phosphorus } \\
\text { (mg/dL) }\end{array}$ & $\begin{array}{c}\text { Parathyroid } \\
\text { Hormone }(\mathrm{\rho g} / \mathrm{mL})\end{array}$ & $\begin{array}{c}\text { Transferrin } \\
\text { saturation (\%) }\end{array}$ \\
\hline 1 & Male & (4) & NO & v.ru & 1.04 & 8.4 & $\varepsilon$ & $\varepsilon \varepsilon$. & 29.30 \\
\hline r & Male & $\Delta \varphi$ & NO & $1 . . r T$ & 0.61 & 8.1 & 3.3 & 299 & 17.52 \\
\hline r & Male & $\Lambda$. & Yes & $v \cdot . r I$ & 0.75 & 9.9 & 5.8 & 320 & 22.91 \\
\hline r & Male & is & No & $r \cdot . r Y$ & 0.80 & 8.5 & 6.6 & V.. & 44.64 \\
\hline$\Delta$ & Female & $\Delta r$ & Yes & V.ro & 1.60 & 8.6 & 5.7 & v. . & 19.11 \\
\hline 9 & Female & $\Delta r$ & Yes & F. r. & 1.05 & 8.2 & 5.6 & $\varepsilon \ldots$ & 19.28 \\
\hline V & Female & vr & Yes & r. r. G & 1.04 & 9.3 & 3.4 & 300 & 30.11 \\
\hline$\wedge$ & Female & G. & Yes & f..rv & 1.06 & 8.3 & 7.6 & 280 & 17.45 \\
\hline 9 & Male & $\Delta F^{r}$ & NO & r. r.r & 1.17 & 8.1 & 8.3 & $r 90$ & 26.13 \\
\hline 1. & Male & $\Delta$. & NO & $v \cdot . r q$ & 1.30 & 8.1 & 5.6 & $9 .$. & 29.62 \\
\hline 11 & Male & $4 q$ & Yes & r...r & 1.61 & 7.8 & 7.2 & $9 .$. & 21.89 \\
\hline IT & Female & VY & Yes & G. To & 1.65 & 8.5 & 3.9 & $9 .$. & 19.57 \\
\hline r & Female & GY & Yes & c.r. & 1.10 & 8.5 & 5.5 & 300 & 28.23 \\
\hline 14 & Male & gr & Yes & $\Delta \cdot . r \Delta$ & 1.03 & 9.1 & 6.1 & $7 \ldots$ & 21.75 \\
\hline 10 & Female & is & Yes & ..T\& & 1.30 & 8.8 & 6.3 & $\Lambda$. & $1 \wedge .20$ \\
\hline 19 & Female & 90 & NO & $r . r \Delta$ & 1.10 & 8.5 & 0 & 300 & 23.75 \\
\hline IV & Male & $\Delta r$ & NO & $r . . T_{1}$ & 1.30 & 8.7 & 7.3 & $0 .$. & 21.14 \\
\hline 11 & Female & $\Delta \Delta$ & Yes & 40.00 & 0.97 & 9 & 6.1 & 90. & 27.35 \\
\hline 19 & Female & 90 & Yes & G.r. & 1.03 & 8.5 & 4.5 & 700 & 25.49 \\
\hline r. & Male & $9 \mathrm{~V}$ & Yes & q.r. & 1.30 & 8.8 & r & $\Lambda$. & 19.84 \\
\hline TI & Male & q. & Yes & $r . . r V$ & 1.10 & 9 & 4.9 & $7 V$. & 21.54 \\
\hline Means & TI & 58.10 & & VT.rT & 1.01 & 8.6 & 5.5 & 682.5 & 24.57 \\
\hline
\end{tabular}


(before or after crossover) among patients who completed the study were $24.19 \pm 7.96$ and $18.89 \pm 11.15(P=0.09$; Figure 2).

\section{Discussion}

Restless legs syndrome has been described for more than 6 decades, however the pathophysiology of RLS is not known exactly. The remission of RLS symptom with gamma-aminobutyric acid (GABA) analogues and dopamine agonists (even in the low-doses) and the exacerbation of RLS symptom with dopamine antagonists support a central role for central nervous system (CNS) dopamine imbalance on the pathogenesis of RLS (1115). For example, opiates, bromocriptine, L-dopa, and benzodiazepines which are shown to be effective in the treatment of RLS act as dopaminergic agonists (5-8).

Gabapentin, a structural analogue of GABA, is an anticonvulsant drug which is also administered for a variety of different conditions (12-18). It has been demonstrated that gabapentin modulates various receptor sites and alters dopamine release (16-19). It has also been suggested that gabapentin reduces neuropathic pain in rats by decreasing abnormal neural excretion and increasing verge of nerve activation (15-19). In the management of RLS and associated sleep disturbance, gabapentin is an attractive therapeutic option compared to other dopamine agonists, because of its relative lack of interactions (15-25). In addition, gabapentin at a low dosage is generally well tolerated with minor side effects including sedation, dizziness, and unsteadiness, especially in older adults. Various studies are available regarding the efficacy of gabapentin in management of RLS among general population, however its effect among HD patients with RLS is not investigated enough.

Our study showed that gabapentin at a dose of 100 mg was a safe effective therapy for RLS. It significantly reduced the intensity of RLS among our HD patients. The dosage of gabapentin which was administered in our trial was a low dosage of $100 \mathrm{mg}$ three times a week. To our knowledge, this is the first study that verified the beneficial impact of gabapentin at a low dosage, in the management of RLS among HD patients.

In addition, gabapentin was well tolerated in our study which appears that it may be due to the low dosage of the drug. The elimination half-life of gabapentin is very long in uremic individuals especially in anuric subjects. It is increased to around 132 hours on non-HD days. However the apparent half-life is reduced to 3.8 hours during dialysis days among ESRD patients undergoing maintenance HD. Therefore, it should be noted that the dosage of gabapentin should be reduced among patients with compromised kidney function or ESRD.

The results of our study are supported by the results of Thorp et al and Micozkadioglu et al $(25,26)$. Thorp et al evaluated the efficacy and safety of gabapentin in the treatment of RLS among $16 \mathrm{HD}$ patients. They were

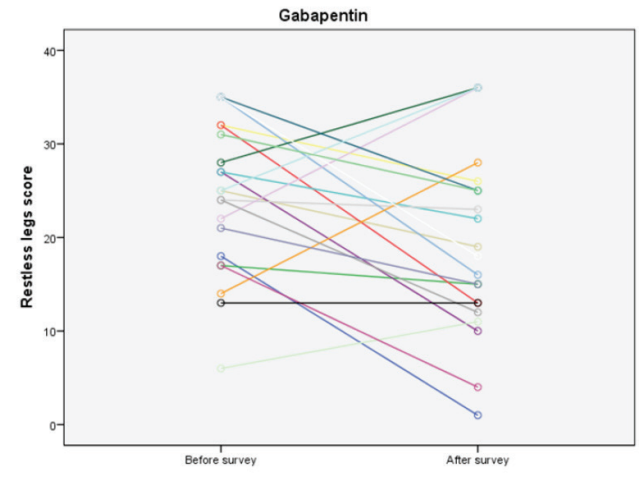

Figure 1. Gabapentin group before and after the study $(P=0.04)$.

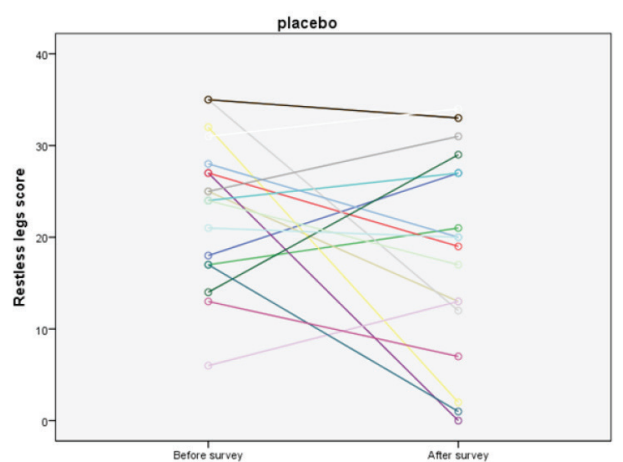

Figure 2. Placebo group before and after the study $(P=0.04)$.

administered gabapentin at a dose of 200 to $300 \mathrm{mg}$ after each HD session. The results of the study showed, significant percent of patients were responded to gabapentin, which was similar to results of our study (25).

Micozkadioglu et al compared the efficacy of gabapentin and levodopa on the treatment of RLS among 15 HD patients (26). Levodopa is a well-known dopamine agonist for the management of this disorder among general population. Gabapentin was administrated at a dose of $200 \mathrm{mg}$ after each HD session. They found both gabapentin and levodopa are effective for management of RLS among HD patients. However when they compared the two drugs for severity of RLS symptoms relief, the effect of gabapentin was significantly superior to levodopa. In addition the effect of gabapentin was also more significant in the improvement of sleep parameters including sleep quality, sleep latency and sleep disturbance (26).

Although the result of above studies and also our study suggested that gabapentin is a safe effective therapy for RLS among ESRD patients, however they are limited by short duration and small proportion of patients. Therefore other multicenter clinical trials with long-duration and larger proportion of patients are needed to determine the effect of gabapentin for treatment of RLS among uremic patients $(27,28)$. 
Although gabapentin did not induce any adverse effect in our study, few side effects in Micah et al and Micozkadioglu et al studies were detected. However it may be associated with significant adverse effects including somnolence, dizziness, asthenia, ataxia, fatigue and convulsion especially at higher doses (28-30).

However, there is a possibility that gabapentin may cause reversible acute kidney injury among kidney transplant patients by a mechanism involving renal afferent vasoconstriction. Serious skin eruptions such as Stevens-Johnson's syndrome have also reported in another case reports. Thus caution during administration of this drug is necessary (28-30).

\section{Conclusion}

Our study showed that gabapentin at the end of HD was effective therapy for RLS. It significantly reduced the intensity of RLS among our ESRD patients. The dosage of gabapentin which was administered in our trial was at a low dosage of $100 \mathrm{mg}$ three times a week.

\section{Limitations of the study}

Our study had two limitations. 1) This is a single center study. 2) Limited proportion of patients.

\section{Authors' contribution}

SSBM, FH, LS and GAA conceived the study and collected the data from study participants. SSBM, LS, SMMM and SAH drafted the manuscript. SSBM prepared the final manuscript. All authors read, revised, and approved the final manuscript.

\section{Conflicts of interest}

There were no points of conflicts.

\section{Ethical considerations}

Ethical issues (including plagiarism, data fabrication, double publication) have been completely observed by the authors.

\section{Funding/Support}

This study was supported by Chronic Renal Failure Research Center, Ahvaz Jundishapur University of Medical Sciences. This manuscript was extracted from residential thesis of Gholamreza Alizadeh Attar.

\section{References}

1. Beladi Mousavi SS, Alemzadeh Ansari MJ, Cheraghian B. Outcome of patients on hemodialysis in Khuzestan, Iran. NDT Plus. 2011;4(2):143-4. doi:10.1093/ndtplus/sfq207.

2. Ghaderian SB, Beladi-Mousavi SS. The role of diabetes mellitus and hypertension in chronic kidney disease. J Renal Inj Prev. 2014;3:109-10. doi: 10.12861/jrip.2014.31.

3. Zelmer JL. The economic burden of end-stage renal disease in Canada. Kidney Int. 2007;72:1122-9.

4. Xue JL, Ma JZ, Louis TA, Collins AJ. Forecast of the number of patients with end-stage renal disease in the United States to the year 2010. J Am Soc Nephrol. 2001;12:2753-8.

5. Kim J, Kwon H, Lim C, Kim Y, Lee S, Nam H. Restless legs syndrome in patients on hemodialysis: symptom severity and risk factors. J Clin Neurol. 2008;4:153-7.

6. Kawauchi A, Inoue Y, Hashimoto T, Tachibana N, Shirakawa S, Mizutani Y, et al. Restless legs syndrome in hemodialysis patients: health-related quality of life and laboratory data analysis. Clin Nephrol. 2006;66:440-6.

7. Bhowmik D, Bhatia M, Gupta S, Agarwal S, Tiwari S, Dash S. Restless legs syndrome in hemodialysis patients in India: a case controlled study. Sleep Med. 2003;4:143-6.

8. Cirignotta F, Mondini S, Santoro A, Ferrari G, Gerardi R, Buzzi G. Reliability of a questionnaire screening restless legs syndrome in patients on chronic dialysis. Am J Kidney Dis. 2002;40:302-6.

9. Takaki J, Nishi T, Nangaku M, Shimoyama H, Inada T, Matsuyama N, et al. clinical and psychological aspects of restless legs syndrome in uremic patients on hemodialysis. Am J Kidney Dis. 2003;41:833-9.

10. Araujo S, Bruin Vd, Nepomuceno L, Maximo M, Ede FD, Ferrer DC, et al. Restless legs syndrome in end stage renal disease: Clinical characteristics and associated comorbidities. Sleep Med. 2010;11:785-90. doi: 10.1016/j. sleep.2010.02.011.

11. Razeghi E, Sahraian M, Heidari R, Bagherzadeh M. Association of inflammatory biomarkers with sleep disorders in hemodialysis patients. Acta Neurol Belg. 2012;112:45-9. doi: 10.1007/s13760-012-0003-7.

12. Tuncel D, Orhan F, Sayarlioglu H, Isık I, Utku U, Dinc A. Restless legs syndrome in hemodialysis patients: association with depression and quality of life. Sleep Breath. 2011;15:311-5. doi: 10.1007/s11325-010-0382-z.

13. Walters AS. Naiphinich K. Co-morbidity, morbidity and mortality in the restless legs syndrome. Sleep Med. 2007;4:11-47.

14. Hanly PJ, Pierratos A, Mucsi I, Novak M. Sleep disorders in end-stage renal disease. Curr Opin Pulm Med. 2008;14:54350. doi: 10.1097/MCP.0b013e3283130f96.

15. Cornella CL. Restless legs syndrome: treatment with dopaminergic agents. Neurology 2002;58(4);S87-92.

16. Happe S, Klösch G, Saletu B, Zeitlhofer J. Treatment of idiopathic restless legs syndrome (RLS) with gabapentin. Neurology. 2001;57:1717-9.

17. Allen R. Dopamine and iron in the pathophysiology of restless legs syndrome (RLS). Sleep Med. 2004;5:385-91.

18. Cervenka S, Palhagen SE, Comley RA, Panagiotidis G, Cselenyi Z, Matthews JC, et al. Support for dopaminergic hypoactivity in restless legs syndrome: a PET study on D2receptor binding. Brain. 2006;129:2017-28.

19. Yoon MH, Yaksh TL. The effect of intrathecal gabapentin on pain behavior and hemodynamics on the formalin test in the rat. Anesth Analg. 1999;89(2):434-39.

20. Mariano S, Paolo R, Patrizio C, Gabriele V, Leoluca P, Francesco P. Gabapentin treatment for muscle cramps: an open-label trial. Clin Neuropharmacol. 2000;23:45-9.

21. Richens A. Clinical pharmacokinetics of gabapentin. In: Chadwick D, ed. New Trends in Epilepsy Management: The Role of Gabapentin. London: Royal Society of Medicine; 1993:41-6.

22. Beydoun A, Uthman BM, Sackellares C: Gabapentin: Pharmacokinetics, efficacy and safety. Clin Neuropharmacol. 1995;18:469-481. 
23. Yoon MH, Yaksh TL. The effect of intrathecal gabapentin on pain behavior and hemodynamics on the formalin test in the rat. Anesth Analg 1999;89:434-39.

24. Wong MO, Eldon MA, Keane WF, Türck D, Bockbrader HN, Underwood BA, et al. Disposition of gabapentin in anuric subjects on hemodialysis. J Clin Pharmacol. 1995;35:622-6.

25. Thorp ML, Morris CD, Bagby SP. A crossover study of gabapentin in treatment of restless legs syndrome among hemodialysis patients. Am J Kidney Dis. 2011;38:34-8.

26. Micozkadioglu H, Ozdemir FN, Kut A, Sezer S, Saatci U, Haberal M. Gabapentin versus levodopa for the treatment of Restless Legs Syndrome in hemodialysis patients: an open-label study. Ren Fail. 2004;26:393-7.
27. Ramsay RE. Gabapentin toxicity. In: Levy, RH, Mattson, RH, Meldrum, BS, eds. Antiepileptic Drugs. 4th ed. New York: Raven Press; 1995:857-60.

28. McLean MJ, Morrell MJ, Willmore LJ, Privitera MD, Faught RE, Holmes GL, et al. Safety and tolerability of gabapentin as adjunctive therapy in a large, multicenter study. Epilepsia 1999; 40: 965-72.

29. Gallay BJ, De Mattos AM, Norman DJ. Reversible acute renal allograft dysfunction due to gabapentin. Transplantation. 2000;70:208-9.

30. Gonzalez-Sicilia L, Cano A, Serrano M, Hernandez J. Stevens-Johnson syndrome associated with gabapentin. Am J Med. 1998;105:455.

Copyright $\odot 2018$ The Author(s); Published by Society of Diabetic Nephropathy Prevention. This is an open-access article distributed under the terms of the Creative Commons Attribution License (http://creativecommons.org/licenses/by/4.0), which permits unrestricted use, distribution, and reproduction in any medium, provided the original work is properly cited. 